\title{
Avaliação de linguagem em um caso de associação entre surdez e paquigiria
}

\section{Language evaluation in a case of association between deafness and pachygyria}

\author{
Milena Rizzon ${ }^{1}$, Deisi Cristina Gollo Marques Vidor ${ }^{1}$, Carina Rebello Cruz ${ }^{2}$
}

\begin{abstract}
RESUMO
Para que ocorra a aquisição e o desenvolvimento da linguagem é necessária a associação de uma série de fatores, cujo funcionamento harmonioso determina o sucesso desse processo. O comprometimento auditivo pode ser um obstáculo, mas, mesmo assim, a criança surda será capaz de adquirir linguagem por meio de uma língua de sinais. Porém, quando a criança apresenta alterações neurológicas, o acompanhamento fonoaudiológico se faz necessário. Esta pesquisa é um estudo de caso sobre uma criança surda, com idade de 5 anos e 10 meses, em processo de aquisição da língua de sinais, com comprometimento neurológico. Tem como objetivo avaliar, analisar e aprofundar conhecimentos sobre uma doença rara (paquigiria), associada com surdez, mostrando os impactos que isso pode acarretar à criança, em relação à comunicação. A coleta de dados foi efetuada por meio de avaliações formais e observacionais sobre habilidade e modalidade de comunicação utilizada, desenvolvimento linguístico, fonologia e conhecimento lexical na Língua Brasileira de Sinais (LIBRAS), além da aplicação de um questionário. Os resultados apontaram atraso no processo de aquisição de linguagem, mesmo considerando-se a defasagem entre o nascimento da criança e o início da aquisição da LIBRAS, aspectos que podem estar relacionados com o diagnóstico de paquigiria. É importante que o fonoaudiólogo conheça a LIBRAS e saiba avaliar a linguagem da criança utente dessa língua, pois casos como estes revelam a complexidade da associação entre surdez e quadros neurológicos variados.
\end{abstract}

Descritores: Estudos de Casos; Fonoaudiologia; Linguagem Infantil; Lisencefalia; Neurologia; Surdez

\begin{abstract}
In order for the acquisition and development of language to occur, it is necessary to associate a number of factors, whose harmonious functioning determines the success of this process. The hearing loss may be an obstacle, but even so, the deaf child will be able to acquire language through a sign language. However, when the child shows neurological changes, the speech monitoring becomes necessary. This research is a case study of a deaf child, aged 5 years and 10 months, in the acquisition of sign language, who presents neurological impairment. It aims to assess, analyze, and deepen the knowledge on a rare disease (pachygyria) associated with deafness, showing the impact that this can pose to the child regarding communication. Data collection was done through formal evaluations and observational regarding the ability and modality used for communication, language development, phonological and lexical knowledge in Brazilian Sign Language (LIBRAS); in addition to a questionnaire. The results showed delay in language acquisition, even considering the gap between the child's birth and the early acquisition of LIBRAS, aspects that may be related to the diagnosis of pachygyria. It is important that the audiologist know LIBRAS and know to assess the language of the child who uses this language, because cases like these reveal the complexity of the association between deafness and various neurological disorders.
\end{abstract}

Keywords: Case studies; Speech, Child Language; Lissencephaly; Neurology; Deafness

Trabalho realizado no Curso de Fonoaudiologia, Universidade Federal de Ciências da Saúde de Porto Alegre - UFCSPA - Porto Alegre (RS), Brasil.

(1) Curso de Fonoaudiologia, Universidade Federal de Ciências da Saúde de Porto Alegre - UFCSPA - Porto Alegre (RS), Brasil.

(2) Escola Especial Para Surdos Frei Pacífico, Porto alegre (RS), Brasil.

Conflitos de interesses: Não

Contribuição dos autores: $M R$ pesquisador principal, elaboração da pesquisa, elaboração do cronograma, levantamento da literatura, coleta e análise dos dados, redação do artigo, submissão e trâmites do artigo; $D C G M V$ orientadora, elaboração da pesquisa, elaboração do cronograma, análise dos dados, correção da redação do artigo, aprovação da versão final; $C R C$ coorientadora, colaboração na elaboração da pesquisa e do cronograma, análise dos dados, correção da redação do artigo, aprovação da versão final.

Endereço para correspondência: Milena Rizzon. R. Genésio Preto, 150, Desvio Rizzo, Caxias do Sul (RS), Brasil, CEP:95110-320.

E-mail: mi.rizzon@hotmail.com

Recebido em: 17/4/2013; Aceito em: 21/8/2013 


\section{INTRODUÇÃO}

A integridade e o funcionamento normal do sistema auditivo, a maturação do sistema nervoso central, o adequado desenvolvimento cognitivo e a integridade dos órgãos fonoarticulatórios são necessários para aquisição e desenvolvimento normais da linguagem oral ${ }^{(1)}$. Quando qualquer desses aspectos se encontra comprometido, presencia-se, inevitavelmente, transtornos de comunicação em maior ou menor grau, dependendo tanto do aspecto afetado, quanto do nível da alteração.

O caso que será apresentado neste artigo é de uma associação entre paquigiria e surdez, denotando alteração no processo de aquisição da linguagem, causada pelo comprometimento do sistema nervoso central, por um lado, e associado ao comprometimento auditivo sensorial, por outro. Embora a paquigiria não tenha relação direta com a surdez, aquela pode vir a ser a causa desta, devido à possíveis alterações nos neurônios da via auditiva central.

A paquigiria é uma doença do desenvolvimento do sistema nervoso, ocasionada por distúrbios da migração neuronal. Nesta malformação, observa-se que o aspecto externo dos hemisférios cerebrais apresenta-se alterado, sendo as circunvoluções anormalmente amplas, planas, com redução do número de sulcos, assemelhando-se às de um feto com idade entre 6 e 7 meses. Pode ser encontrada na totalidade do cérebro, ou em áreas localizadas em um ou ambos os hemisférios ${ }^{(2)}$.

O fechamento do diagnóstico da paquigiria é obtido através da avaliação clínica e de exames de imagem. No exame neurológico geralmente estão presentes atraso do desenvolvimento motor e de linguagem, retardo mental, hipotonia global e déficit de equilíbrio ${ }^{(3)}$.

Por outro lado, o comprometimento sensorial auditivo causado pela surdez também gera déficits no processo de aquisição da linguagem oral. O impacto dessa alteração depende de uma série de fatores, tais como o grau da perda, o momento da detecção da surdez e a utilização de ferramentas que possam auxiliar o indivíduo surdo ${ }^{(1)}$. No entanto, a falta da audição, de forma isolada, não é impedimento para a organização da realidade experimentada através da linguagem ${ }^{(4)}$. O pleno domínio desse aspecto depende do aprendizado dos componentes funcionais da competência linguística - forma (fonologia, morfologia e sintaxe), conteúdo (semântica) e uso intencional (pragmática) $^{(5)}$. Essa competência pode ser adquirida tanto por meio da aquisição de uma língua de modalidade oral, como o Português Brasileiro, como também por meio da aquisição de uma língua de modalidade visuoespacial, como a língua brasileira de sinais (LIBRAS).

A LIBRAS é oficialmente conceituada como forma de comunicação e expressão em que o sistema visual motor, com sua própria estrutura gramatical, constitui um sistema linguístico de transmissão de ideias e fatos, assim como as línguas de modalidade auditivo-orais ${ }^{(6)}$. Entende-se que deve tornar-se a língua materna, ou primeira língua da população surda, quando não é possível a utilização da língua oral para a comunicação $^{(7)}$. Quando a criança surda recebe o estímulo da sua língua materna desde o nascimento, geralmente não são verificados atrasos de linguagem, como ocorre em crianças ouvintes expostas às línguas orais. No entanto, essa não é a realidade da grande maioria das crianças surdas cujos pais são sujeitos ouvintes, desconhecedores da LIBRAS. A não exposição precoce e contínua a essa língua, associada à falta de feedback auditivo das línguas orais, pode comprometer o desenvolvimento linguístico da criança ${ }^{(8)}$.

Mesmo considerando-se a situação de exposição ideal e precoce à LIBRAS, crianças surdas também podem vir a desenvolver alterações em seu processo de aquisição de linguagem em língua de sinais, devendo ser encaminhadas à terapia fonoaudiológica, com o objetivo de aperfeiçoar sua linguagem e melhorar a interação social e qualidade de vida.

Além disso, a presença de comorbidades que comprometam outros aspectos essenciais para o processo de aquisição da linguagem, como aquelas que afetam o desenvolvimento cognitivo e motor, aumenta os riscos de prejuízo nessa área ${ }^{(1)}$.

Desse modo, justifica-se a importância deste estudo, que teve como objetivo avaliar, analisar e aprofundar conhecimentos sobre uma doença rara e complexa, associada à surdez, mostrando os impactos que isso pode acarretar à criança afetada, em relação a sua comunicação - principalmente no que diz respeito ao processo de aquisição de linguagem - e fazer uma comparação baseada na descrição da literatura sobre a aquisição da linguagem de crianças surdas sem comorbidades, que se utilizam da LIBRAS como primeira língua.

\section{APRESENTAÇÃO DO CASO CLÍNICO}

O caso apresentado neste estudo é de uma criança do gênero feminino, com 5 anos e 10 meses de idade, com diagnóstico de paquigiria e perda auditiva neurossensorial de grau profundo, em ambas as orelhas. A paquigiria, com comprometimento das áreas frontal e parietal no hemisfério direito, foi atestada por médico neurologista em 2011. O diagnóstico da perda auditiva foi obtido em 2008, por meio de avaliações comportamentais, eletroacústicas e eletrofisiológicas. A responsável pela criança assinou o Termo de Consentimento Livre e Esclarecido, concordando com a realização e a divulgação desta pesquisa e seus resultados, de acordo com a Resolução 196/96. Este trabalho foi aprovado pelo Comitê de Ética em Pesquisa da Universidade Federal de Ciências da Saúde de Porto Alegre (UFCSPA), sob parecer número 12/946.

A coleta de dados foi realizada por meio de avaliações formais e observacionais do desenvolvimento da criança em relação à linguagem, envolvendo aspectos de compreensão e expressão nas áreas de pragmática, habilidade e modalidade de comunicação e léxico e fonologia em LIBRAS, juntamente com um questionário aplicado ao responsável. 
No questionário, foram coletados dados sobre o desenvolvimento da menina. $\mathrm{O}$ atendimento fonoaudiológico foi iniciado com 1 ano e 6 meses de idade - em abordagem sinalizada, por meio de sessões semanais com duração de 30 minutos. Com 2 anos e 6 meses, a menina recebeu a prótese auditiva, porém sempre fez pouco uso do aparelho de amplificação sonora individual. Com 4 anos, foi diagnosticada com paquigiria e ingressou em uma escola bilíngue para surdos (LIBRAS Português escrito), onde tem aulas com uma professora surda, nativa na LIBRAS. Em casa, a menina consegue se comunicar através da LIBRAS, gestos e linguagem própria. A família, ouvinte, fez curso de LIBRAS e conhece alguns sinais, mas usa também gestos próprios para se comunicar com a criança.

Para avaliar aspectos da linguagem formalmente, foram utilizados três protocolos: "Avaliação da língua de sinais em crianças surdas na escola"(9), utilizada para observar e registrar o desenvolvimento da criança em relação à linguagem (compreensão e produção), determinando o seu nível de aquisição; "Protocolo de Avaliação das Habilidades de Comunicação e de Linguagem para Crianças Surdas: Perfil Pragmático da Criança Surda" ${ }^{(10)}$, que avalia as habilidades pragmáticas e a modalidade de comunicação da criança; "Proposta de instrumento de avaliação da consciência fonológica, parâmetro configuração de mão, para crianças surdas utentes da Língua de Sinais Brasileira" ${ }^{(11)}$, que foi utilizada para avaliação da proficiência lexical e fonológica em LIBRAS. As avaliações foram registradas por filmadora, para serem analisadas em um momento posterior.

A "Avaliação da língua de sinais em crianças surdas na escola" é composta por testes de quantificação de desenvolvimento e de acompanhamento (teste somático e teste formativo, respectivamente). Foi aplicado o teste formativo e parte de produção do teste somático, devido às dificuldades da criança.

No caso do teste formativo, o profissional dispõe de um instrumento para observar e registrar o desenvolvimento da criança em relação à linguagem, determinando o seu nível de aquisição. Os critérios avaliados referem-se à compreensão e à expressão da linguagem: referência, conteúdo, coesão, uso e forma. Os níveis de desenvolvimento avaliados são divididos em $0+$ ( 0 aos 12 meses), 1 (por volta de 1 ano), 2 ( 2 a 3 anos), 3 (3 a 4 anos), 4 (4 a 5 anos), 5 (5 a 6 anos), 6 (6 a 7 anos) e 7 (11 a 13 anos), de acordo com as características de linguagem da criança, em relação à idade.

Para aplicar o teste, deve-se determinar o nível de entendimento e uso da linguagem da criança, através de observação e atividades lúdicas; iniciar as questões com o nível anterior; responder às questões até chegar a uma resposta negativa; determinar o nível em que a criança se encontra, que corresponderá ao nível mais alto, no qual todas as respostas assinaladas forem positivas; determinar se a criança apresenta o nível (+), que indica que ela tem a maioria das questões do determinado nível imediatamente superior àquele em que foi classificada.

A criança deste caso foi inicialmente classificada no nível 2 (2 a 3 anos), conforme seu uso e entendimento da linguagem. No nível 2, espera-se que a criança produza sinais para falar sobre coisas e ações presentes; que o uso da linguagem esteja ligado às funções que visam chamar a atenção das pessoas; faça pedidos e reclame e se comunique mais do que é capaz de produzir explicitamente, possibilitando aos outros entenderem o que ela deixou de dizer.

A partir dessa classificação inicial, o teste formal foi aplicado e a menina permaneceu no nível 2 , confirmando a observação da terapeuta (Quadro 1).

Para a avaliação de produção deste instrumento, foi selecionada uma história - desenho animado sem fala "Tom e Jerry" (com sete fatos) - que a criança deveria assistir e relatar para uma terceira pessoa que não tivesse assistido ao desenho. A avaliação da sua produção é descritiva, analisando-se o uso de mecanismos da estrutura da língua de sinais, tais como estabelecimento de referentes no espaço, concordância verbal e classificadores*.

A criança assistiu ao vídeo de um minuto e meio, prestando atenção durante todo o tempo. Quando solicitado para contar a história, utilizou estrutura sintática simples, usando apenas apontamentos e classificadores. Primeiramente, apontou para o computador, referindo-se ao personagem e executou o classificador de aumentar o volume do rádio. Depois, apontou novamente para o computador e imitou o gato rindo.

O "Protocolo de Avaliação das Habilidades de Comunicação e de Linguagem para Crianças Surdas: Perfil Pragmático da Criança Surda" trata de uma lista de habilidades comunicativas, compreendidas em três seções: intenções comunicativas, resposta à comunicação e interação e conversação. Essas habilidades devem ser observadas através de uma atividade lúdica semiestruturada. A análise das funções e habilidades comunicativas deve ser efetuada levando-se em consideração a presença ou ausência de cada aspecto e, no caso da presença, qual a modalidade de comunicação utilizada pela criança língua de sinais, língua oral, gestos ou vocalizações - e a fase linguística em que se encontra - não linguística, linguística oral ou linguística de sinais.

A criança realizou a maioria dos tópicos observados (92\%) de maneira consistente. Alguns dos tópicos avaliados foram realizados em mais de uma modalidade de comunicação, sendo a maior parte na modalidade gesto (76\%), seguida da modalidade língua de sinais (60\%) e vocalização (12\%) (Quadro 2).

A "Proposta de instrumento de avaliação da consciência fonológica, parâmetro configuração de mão, para crianças

\footnotetext{
* Os referentes introduzidos no discurso da LIBRAS podem ser associados a pontos específicos no espaço da sinalização. Esses pontos no espaço passam a fazer referência aos referentes que os introduziram. O uso adequado dos referentes é o primeiro passo para o estabelecimento da concordância verbal e para o uso dos demais mecanismos sintáticos espaciais. O classificador pode representar algum referente.
} 
Quadro 1. Questões marcadas nos níveis da "Avaliação da língua de sinais em crianças surdas na escola"

\begin{tabular}{|c|c|c|c|}
\hline \multicolumn{4}{|c|}{ Nível 1 (em torno de 1 ano) } \\
\hline Critério & Pergunta-chave & Sim & Não \\
\hline 1 & A criança refere aos objetos através da apontação, segurando, olhando e tocando-os? & $\mathrm{X}$ & \\
\hline 2 & A criança se comunica referindo aos brinquedos, luzes, objetos, animais e alimentos? & $\mathrm{X}$ & \\
\hline 3 & A criança começa a ter iniciativa e participa de outras atividades, como colocar e tirar objetos com o outro? & $\mathrm{X}$ & \\
\hline 3 & A criança imita movimentos produzidos por outros? & $\mathrm{X}$ & \\
\hline 4 & Ela utiliza uma linguagem não verbal para chamar a atenção para necessidades pessoais? & $\mathrm{X}$ & \\
\hline 4 & Ela utiliza uma linguagem não verbal para expressar suas reações? & $\mathrm{X}$ & \\
\hline 4 & $\begin{array}{l}\text { Ela utiliza uma linguagem não verbal para pedir ajuda variando seu olhar entre o objeto e a pessoa } \\
\text { que a ajuda a pegar o objeto? }\end{array}$ & $\mathrm{X}$ & \\
\hline 5 & A criança imita sinais apesar de apresentar configurações de mão e movimentos imperfeitos? & $\mathrm{X}$ & \\
\hline \multicolumn{4}{|c|}{ Nível 2 (2 a 3 anos) } \\
\hline Critério & Pergunta-chave & Sim & Não \\
\hline 1 & A criança produz palavras isoladas ou sinais para falar sobre coisas e ações ao redor delas? & $\mathrm{X}$ & \\
\hline 2 & A criança identifica o objeto ao ser referido por outro? & $\mathrm{X}$ & \\
\hline 3 & A criança as vezes repete o que foi dito? & $\mathrm{X}$ & \\
\hline 4 & A criança usa a linguagem para fazer pedidos? & $\mathrm{X}$ & \\
\hline 4 & A criança usa a linguagem para chamar a atenção de outros para si ou para sua localização? & $\mathrm{X}$ & \\
\hline 4 & A criança usa a linguagem para dizer "oi", "tchau", etc? & $\mathrm{X}$ & \\
\hline 4 & A criança usa a linguagem para reclamar? & $\mathrm{x}$ & \\
\hline 4 & A criança usa a linguagem para nomear objetos? & $\mathrm{X}$ & \\
\hline 4 & A criança usa a linguagem para notar a presença de objetos? & $\mathrm{X}$ & \\
\hline 4 & A criança usa a linguagem para expressar que objetos desapareceram (ou foram removidos)? (acabou...) & $\mathrm{X}$ & \\
\hline 5 & A criança aponta, olha, toca, identifica as coisas sobre as quais está falando com significado? & $\mathrm{X}$ & \\
\hline \multicolumn{4}{|c|}{ Nível 3 (3 a 4 anos) } \\
\hline Critério & Pergunta-chave & Sim & Não \\
\hline 1 & A criança refere às coisas de seu interesse? & $\mathrm{X}$ & \\
\hline 2 & A criança fala sobre coisas e fatos que a envolve? & $\mathrm{X}$ & \\
\hline 2 & A criança fala sobre a localização dos objetos? & & $\mathrm{X}$ \\
\hline 2 & A criança fala sobre o destino dos objetos quando estes foram removidos ou estão sendo removidos? & & $\mathrm{X}$ \\
\hline 2 & A criança fala sobre características temporárias ou mais ou menos permanentes de objetos e coisas? & & $\mathrm{X}$ \\
\hline 2 & A criança fala sobre as coisas que pertencem a si e aos outros? & $\mathrm{X}$ & \\
\hline 3 & A criança consegue relacionar o que fala com o que os outros estão falando de alguma forma? & & $\mathrm{x}$ \\
\hline 4 & A criança usa a linguagem para representar suas ações? & $\mathrm{x}$ & \\
\hline 4 & $\begin{array}{l}\text { A criança usa a linguagem para notar a presença de vários objetos e para expressar que objetos } \\
\text { desapareceram (ou foram removidos) e reapareceram? }\end{array}$ & & $\mathrm{X}$ \\
\hline 4 & A criança usa a linguagem para fazer diferentes tipos de pedidos? & & $\mathrm{X}$ \\
\hline 4 & A criança usa a linguagem para identificar coisas e ações em figuras? & $\mathrm{x}$ & \\
\hline 5 & A criança usa de forma consistente frases com no mínimo dois componentes sintaticamente relacionados? & & $\mathrm{X}$ \\
\hline 5 & A criança oferece informações suficientes para as pessoas compreenderem a sua intenção? & & $\mathrm{X}$ \\
\hline
\end{tabular}

Legenda: 1 = referência; 2 = conteúdo; 3 = coesão; 4 = uso; 5 = forma

surdas utentes da Língua de Sinais Brasileira" é composta de duas partes. Porém, devido à faixa etária e pré-requisito, só foi aplicada a primeira parte do teste, em que se avaliou a proficiência lexical e fonológica, ou seja, os conhecimentos do informante em relação ao vocabulário solicitado no instrumento e a forma como esses sinais são produzidos.
No instrumento, a criança deve denominar 120 figuras familiares. Em relação à atribuição do significado e como os sinais são produzidos, as realizações da criança podem ser classificadas em cinco categorias: Denominação esperada (DE); Denominação não esperada (DNE); Denominação esperada modificada (DEM); Comentário, classificador ou mímica (C/ 
Quadro 2. Tópicos marcados em suas referentes modalidades de comunicação, do "Protocolo de Avaliação das Habilidades de Comunicação e de Linguagem para Crianças Surdas"

\begin{tabular}{|l|c|c|c|c|c|}
\hline Tópicos & \multicolumn{5}{|c|}{ Observação } \\
\hline Intenções comunicativas & $\mathrm{G}$ & $\mathrm{V}$ & LO & LS & NA \\
\hline Ganhando atenção & $\mathrm{X}$ & & & & \\
\hline Solicitando & $\mathrm{X}$ & & & $\mathrm{X}$ & \\
\hline Rejeitando & $\mathrm{X}$ & & & $\mathrm{X}$ & \\
\hline Cumprimentando & & & & $\mathrm{X}$ & \\
\hline Expressando & $\mathrm{X}$ & $\mathrm{X}$ & & $\mathrm{X}$ & \\
\hline Nomeando & $\mathrm{X}$ & & & $\mathrm{X}$ & \\
\hline Comentando & $\mathrm{X}$ & & & $\mathrm{X}$ & \\
\hline Informando & & & & $\mathrm{X}$ & \\
\hline Respostas para comunicação & & & & & \\
\hline Obtendo atenção & $\mathrm{X}$ & & & $\mathrm{X}$ & \\
\hline Interesse & $\mathrm{X}$ & $\mathrm{X}$ & & $\mathrm{X}$ & \\
\hline Compreendendo gestos & $\mathrm{X}$ & & & & \\
\hline Reconhecendo & $\mathrm{X}$ & & & & \\
\hline Compreendendo intençães & $\mathrm{X}$ & & & & \\
\hline Antecipação & & & & $\mathrm{X}$ & \\
\hline Respondendo com diversão & $\mathrm{X}$ & $\mathrm{X}$ & & & \\
\hline Negociando & $\mathrm{X}$ & & & & \\
\hline Interação e conversação & & & & & \\
\hline Iniciando & $\mathrm{X}$ & & & & \\
\hline Mantendo & $\mathrm{X}$ & & & $\mathrm{X}$ & \\
\hline Inteligibilidade & $\mathrm{X}$ & & & $\mathrm{X}$ & \\
\hline Pressuposição & & & & $\mathrm{X}$ & \\
\hline Reparo & $\mathrm{X}$ & & & $\mathrm{X}$ & \\
\hline Pedido clareza & $\mathrm{X}$ & & & & $\mathrm{X}$ \\
\hline Terminando & $\mathrm{X}$ & & & $\mathrm{X}$ & \\
\hline Ouvindo & & & & & $\mathrm{X}$ \\
\hline Participando & & & & $\mathrm{X}$ \\
\hline
\end{tabular}

Legenda: $\mathrm{G}$ = gesto; $\mathrm{V}=$ vocalização; $\mathrm{LO}$ = língua oral; $\mathrm{LS}$ = Língua de Sinais; $N A$ = não apresentou

CL/Mm) e Não denomina (ND). Ocorre a DE quando a criança realiza a denominação de acordo com a figura e o alvo estabelecido e a DNE, quando uma denominação não corresponde ao alvo estabelecido, mas mantém relação com ele e com a figura apresentada. Quando a criança realiza a denominação de acordo com a figura, porém algum parâmetro é modificado durante a produção, em relação ao sinal padrão (adulto), considera-se uma DEM. C/CL/Mm ocorrem quando a criança realiza um comentário sobre a figura, como "igual ao meu", ou um classificador, como ao representar manualmente o formato do prédio da figura apresentada, ou ainda, mímica, ao fazer o movimento com o pé de 'chutar uma bola'. Se a criança não denominar ou referir não saber o sinal correspondente à figura que visualiza, terá como marcação na tabela o $\mathrm{ND}^{(11)}$.

Se a criança não realizar uma DE, a examinadora denomina a figura e faz comentários sobre a mesma. Ao final da aplicação do teste, a examinadora solicita novamente a denominação de cada figura, cuja produção não foi uma DE. Caso a criança produza, em reavaliação, o fato é marcado na ficha, em "observações".

Das 120 figuras avaliadas, $17(14,2 \%)$ foram denominadas de forma esperada; sete $(5,8 \%)$, de forma não esperada; sete $(5,8 \%)$, de forma esperada modificada; 37 (30,8\%) foram denominadas com comentário, classificador ou mímica e 52 (43,3\%) não foram denominadas (Quadro 3).

Com relação aos sinais produzidos pela criança, também foi avaliada a fonologia. As definições sobre fonologia, na língua oral, referem-se ao estudo dos sistemas de sons. No entanto, a fonologia das línguas de sinais se estabelece a partir de unidades mínimas não sonoras, que formam os sinais ${ }^{(11)}$.

Os parâmetros configuração de mão $(\mathrm{CM})$, ponto de articulação (PA) e movimento (M) são unidades mínimas estudadas na fonologia das línguas de sinais, assim como a orientação da mão (Or) e aspectos não manuais (NM), que se referem às expressões faciais e corporais ${ }^{(11)}$.

As CMs são as diversas formas que a(s) mão(s) toma(m) na realização do sinal. O M pode envolver uma vasta rede de formas e direções, desde os movimentos internos da mão, do pulso, movimentos direcionais no espaço, ou conjuntos de movimentos no mesmo sinal. O PA é o espaço em frente ao corpo ou uma região do mesmo, onde os sinais são articulados. A Or é a direção da palma da mão durante os sinais: cima, baixo, frente, esquerda ou direita. Os NM referem-se aos movimentos da face, dos olhos, da cabeça, ou do tronco ${ }^{(11)}$.

Dos sinais produzidos pela criança, sete tiveram DEM, ou seja, a fonologia estava alterada, de alguma forma, em algum dos parâmetros. Destes, a CM foi o parâmetro que teve mais alteração nas produções da criança, totalizando quatro alterações $(57,1 \%)$; o PA estava alterado em dois sinais $(28,6 \%)$ e a Or em um $(14,3 \%)$.

Além das avaliações formais, foram realizadas observações sobre todos os aspectos do desenvolvimento, tanto no ambiente terapêutico como em sala de aula: A menina demonstra ser afetiva e tranquila, porém dispersa. Não mantém contato visual por muito tempo e o tempo de atenção direcionado às sinalizações e às atividades é abreviado. Compreende sinais e ordens simples, com, no máximo, dois componentes. A linguagem expressiva é ainda mais simples, composta por vocabulário restrito. Realiza apenas sinais isolados, e, alguns deles, pouco inteligíveis. Faz imitação de sinais com frequência, realiza condutas simbólicas ao brincar. Apresenta dificuldade motora ampla e fina e notam-se alterações na marcha e no equilíbrio.

\section{DISCUSSÃO}

A discussão deste caso, que associa a paquigiria à surdez, compara o desempenho obtido pelo sujeito da pesquisa nas avaliações de linguagem com os dados da literatura referentes aos padrões de desenvolvimento esperados para crianças 
Quadro 3. 'Ficha de dados - Parte 1 da "Proposta de instrumento de avaliação da consciência fonológica, parâmetro configuração de mão, para crianças surdas utentes da Língua de Sinais Brasileira"

\begin{tabular}{|c|c|c|c|}
\hline $\mathrm{N}^{\circ}$ & Sinal & Produção & Observações \\
\hline 1 & Amarelo & DEM & PA modificado \\
\hline 2 & Arroz & $\mathrm{CL}$ & Com uma mão imitou o prato de arroz, e com a outra o arroz, como mostrava a figura \\
\hline 3 & Avião & DE & \\
\hline 4 & Azul & DE & \\
\hline 5 & Bailarina & $\mathrm{CL}$ & $\begin{array}{l}\text { Imitou o movimento de dança que a bailarina estava fazendo na figura, e mostrou que } \\
\text { a bailarina estava de rosa como ela, através de apontamentos }\end{array}$ \\
\hline 6 & Balão & ND & \\
\hline 7 & Baleia & DNE & Produziu o sinal 'peixe' \\
\hline 8 & Barata & DNE & Produziu o sinal 'boi'. Expressou reação de medo \\
\hline 9 & Barraca & DEM & Denominou 'casa' com PA modificado \\
\hline 10 & Bebê & DEM & Produziu o sinal 'bebê' com Or modificada \\
\hline 11 & Biblioteca & ND & \\
\hline 12 & Bicicleta & $\mathrm{Mm}$ & Realizou o movimento de pedalar com os pés, e de segurar no guidão com as mãos \\
\hline 13 & Bico & DEM & CM modificada \\
\hline 14 & Boi & $\mathrm{DE}$ & \\
\hline 15 & Bola & DE & \\
\hline 16 & Boné & $\mathrm{DE}$ & \\
\hline 17 & Borracha & ND & \\
\hline 18 & Braba & $\mathrm{Mm}$ & Imitou a expressão facial \\
\hline 19 & Brasil & ND & \\
\hline 20 & Bruxa & ND & Expressou reação de medo \\
\hline 21 & Burro & DNE & Denominou 'boi' \\
\hline 22 & Cachorro & $\mathrm{Mm}$ & Movimento de mordida com a boca \\
\hline 23 & Cadeira & C & Apontou para a cadeira que estava sentada \\
\hline 24 & Cama & $\mathrm{CL}$ & Deitou para trás na cadeira e representou manualmente o formato da cama \\
\hline 25 & Canguru & DE & Depois de denominar 'canguru' fez o sinal 'boi' \\
\hline 26 & Carro & DE & \\
\hline 27 & Casa & $\mathrm{Mm}$ & Fez a mímica de "bater" na porta da casa, na própria figura \\
\hline 28 & Chinelo & C & Apontou para a figura e depois para os pés \\
\hline 29 & Chocolate & $\mathrm{Mm}$ & Gesto de "morder o chocolate" \\
\hline 30 & Chuva & $\mathrm{DE}$ & \\
\hline 31 & Cinco & DEM & CM modificada \\
\hline 32 & Cinza & ND & \\
\hline 33 & Cobra & $\mathrm{Mm}$ & Produziu mordida com a boca, e movimento do bote da cobra. Expressou reação de medo \\
\hline 34 & Coco & $\mathrm{Mm}$ & Produziu o movimento de quebrar o coco e bateu na mesa, expressando "duro" \\
\hline 35 & Coelho & DNE & Produziu o sinal 'boi' \\
\hline 36 & Computador & $\mathrm{Mm}$ & Fez o gesto de digitar algo no teclado do computador, na própria imagem \\
\hline 37 & Copo & C & Referiu 'beber' \\
\hline 38 & Dado & ND & \\
\hline 39 & Doce & $\mathrm{Mm}$ & Fez a mímica de "comer o doce" \\
\hline 40 & Dois & ND & \\
\hline 41 & Edifício & ND & \\
\hline 42 & Elefante & DEM & CM modificada \\
\hline 43 & Escova de dente & DE & \\
\hline 44 & Esmalte & $\mathrm{DE}$ & \\
\hline
\end{tabular}


Quadro 3. continuação

\begin{tabular}{|c|c|c|c|}
\hline $\mathrm{N}^{\circ}$ & Sinal & Produção & Observações \\
\hline 45 & Espelho & $\mathrm{CL}$ & $\begin{array}{l}\text { Imita a moça se olhando no espelho. Repete o sinal da examinadora logo após a } \\
\text { visualização do mesmo }\end{array}$ \\
\hline 46 & Faca & ND & Faz repetição \\
\hline 47 & Feijão & $\mathrm{Mm}$ & $\begin{array}{l}\text { Fez mímica de "comer o feijão". Tenta fazer repetição, porém usa CM e M não } \\
\text { semelhantes às utilizadas na produção do sinal padrão }\end{array}$ \\
\hline 48 & Filho & C & Aponta para ela e para o computador \\
\hline 49 & Futebol & $\mathrm{Mm}$ & Produz mímica de chutar a bola e o sinal 'bola' \\
\hline 50 & Gelatina & ND & $\begin{array}{l}\text { Tentou fazer repetição, porém usa CMs não semelhantes às utilizadas na produção } \\
\text { do sinal padrão }\end{array}$ \\
\hline 51 & Girafa & $\mathrm{CL}$ & Faz as orelhas da girafa. Faz imitação \\
\hline 52 & Guarda-chuva & DE & \\
\hline 53 & Helicóptero & DNE & Denominou 'avião' e fez mímica de "pilotar” \\
\hline 54 & Homem & C & Comentou sobre o cabelo do homem \\
\hline 55 & Jacaré & ND & Demonstrou medo \\
\hline 56 & Jornal & ND & \\
\hline 57 & Leão & $\mathrm{DE}$ & \\
\hline 58 & Leite & $\mathrm{CL}$ & Usou o classificador, "servindo o leite" \\
\hline 59 & Limão & $\mathrm{CL}$ & Produziu a forma do limão \\
\hline 60 & Livro & ND & \\
\hline 61 & Lobo & DNE & Denominou 'leão’ \\
\hline 62 & Lua & C & Refere 'hora de dormir' \\
\hline 63 & Luz acesa & ND & Faz imitação \\
\hline 64 & Luz apagada & ND & \\
\hline 65 & Maçã & $\mathrm{Mm}$ & Fez o movimento de "comer a maçã" \\
\hline 66 & Macaco & C & Comentou sobre os dentes do macaco \\
\hline 67 & Mãe & C & Apontou para ela e para a figura \\
\hline 68 & Meias & C & Mostra as suas meias \\
\hline 69 & Melancia & $\mathrm{Mm}$ & Movimento de "morder" a melancia \\
\hline 70 & Mesa & C & Apontou para a mesa a qual estávamos usando \\
\hline 71 & Milho & ND & \\
\hline 72 & Mochila & DEM & CM modificada \\
\hline 73 & Morcego & $\mathrm{CL}$ & Faz o movimento das asas do morcego. Tenta fazer imitação \\
\hline 74 & Mosquito & ND & Usa expressão facial de medo \\
\hline 75 & Motocicleta & DE & \\
\hline 76 & Mulher & ND & \\
\hline 77 & Navio & $\mathrm{DE}$ & \\
\hline 78 & Nove & ND & \\
\hline 79 & Nuvens & C & Comentou "chove" \\
\hline 80 & Oito & ND & \\
\hline 81 & Onça & $\mathrm{Mm}$ & Fez movimento de mordida \\
\hline 82 & Ônibus & DNE & Denominou 'carro' \\
\hline 83 & Onze & ND & \\
\hline 84 & Pai & C & Apontou para ela e para a figura \\
\hline 85 & Palhaço & $\mathrm{CL}$ & Imitou o palhaço. Faz repetição \\
\hline 86 & Pão & ND & \\
\hline 87 & Papai Noel & ND & \\
\hline
\end{tabular}


Quadro 3. continuação

\begin{tabular}{|c|c|c|c|}
\hline $\mathrm{N}^{\circ}$ & Sinal & Produção & Observações \\
\hline 88 & Pedra & ND & \\
\hline 89 & Picolé & $\mathrm{DE}$ & \\
\hline 90 & Pipa & ND & \\
\hline 91 & Porco & ND & \\
\hline 92 & Presente & ND & \\
\hline 93 & Preto & ND & \\
\hline 94 & Queijo & ND & \\
\hline 95 & Rato & ND & \\
\hline 96 & Refrigerante & $\mathrm{Mm}$ & Fez gesto de "abrir" o refrigerante \\
\hline 97 & Rei & ND & \\
\hline 98 & Rir & ND & \\
\hline 99 & Robô & $\mathrm{DE}$ & \\
\hline 100 & Rosa & ND & \\
\hline 101 & Saia & ND & Procurou alguém usando saia \\
\hline 102 & Sapato & ND & \\
\hline 103 & Sete & ND & \\
\hline 104 & Sol & ND & \\
\hline 105 & Soldado & C & Referiu 'correr' e 'atirar' \\
\hline 106 & Telefone & ND & \\
\hline 107 & Televisão & ND & \\
\hline 108 & Tênis & ND & \\
\hline 109 & Toalha & ND & \\
\hline 110 & Trem & ND & \\
\hline 111 & Triste & ND & \\
\hline 112 & Tucano & ND & \\
\hline 113 & Urso & ND & \\
\hline 114 & Uva & ND & \\
\hline 115 & Vassoura & $\mathrm{DE}$ & \\
\hline 116 & Vela & ND & \\
\hline 117 & Verde & ND & \\
\hline 118 & Vestido & ND & \\
\hline 119 & Videocassete & ND & \\
\hline 120 & Xícara e Pires & ND & \\
\hline
\end{tabular}

Legenda: $\mathrm{DE}$ = denominação esperada; $\mathrm{DNE}=$ denominação não esperada; $\mathrm{DEM}=$ denominação esperada modificada; $\mathrm{C} / \mathrm{CL} / \mathrm{Mm}=\mathrm{comentário,} \mathrm{classificador} \mathrm{ou}$ mímica; $\mathrm{ND}$ = não denomina; $\mathrm{CM}$ = configuração de mão; $\mathrm{M}=$ movimento; $\mathrm{PA}=$ ponto de articulação; $\mathrm{Or}$ = orientação das mãos

surdas, utentes de língua de sinais e filhas de pais ouvintes, com variado período de exposição linguística (PEL). Os resultados também serão comparados com dados da aquisição natural da LIBRAS, elencando, sempre que necessário, possíveis alterações que possam ser atribuídas ao comprometimento gerado pela paquigiria. O principal objetivo é verificar os impactos que esse quadro diagnóstico está acarretando à criança afetada, em relação a sua comunicação.

Quanto à avaliação do desenvolvimento da criança em relação à linguagem, realizada por meio do primeiro protocolo aplicado, percebe-se grande defasagem, mesmo se considerando um atraso no início do processo de aquisição. O protocolo sugere que a criança deveria estar no nível 5, sendo capaz de se comunicar de forma complexa do ponto de vista gramatical e pragmático e fazendo-se compreender por pessoas que the são estranhas. Se considerarmos o tempo de exposição à LIBRAS (língua utilizada para a avaliação) poderíamos pensar que o nível a ser atingido fosse o 4, no qual a comunicação, embora já ampla e complexa, se limita a situações concretas e cotidianas. No entanto, observa-se na comunicação da criança, a falta de componentes que possam torná-la mais inteligível e completa. Mesmo com esta defasagem, ela consegue fazer uso 
da linguagem para atingir seus objetivos, referindo-se às coisas que necessita com sinais isolados e gestos e compreendendo frases com até dois elementos.

A avaliação realizada pelo mesmo instrumento, em relação à produção linguística em sinais, também demonstra defasagem em relação ao esperado. Segundo a aplicação piloto desse protocolo $^{(9)}$, todos os alunos pesquisados utilizaram classificadores de modo satisfatório durante a produção, o que não ocorreu com a criança deste presente estudo, que utilizou esse classificador - considerado o mais básico - porém, de forma escassa e realizado por meio de estrutura sintática simples. A concordância verbal, mesmo sendo o aspecto mais complexo da produção $0^{(9)}$, deveria ser utilizado de forma mais completa nessa idade. No entanto, a criança não alcançou o desempenho esperado, pois a história não teve contexto, nem continuidade, sendo relatada por duas frases sem ligação.

O perfil pragmático de crianças surdas esperado pelo segundo protocolo aplicado é o de adequação e uso de todas as habilidades de comunicação, produzidas, preferencialmente, dentro da modalidade visuoespacial, com utilização de LIBRAS. Estudo realizado ${ }^{(12)}$, observou maior utilização da modalidade visuoespacial (língua de sinais), seguida da língua oral (LO) e da utilização de gestos e vocalizações, mostrando maior complexidade linguística para língua de sinais. A criança deste estudo encontra-se aquém do esperado para sua idade e experiência com a LIBRAS, pois além de não ter utilizado todas as habilidades de comunicação de forma adequada, as fez, em sua maioria, por meio de gestos, como forma de se comunicar, devido à dificuldade na aquisição da língua de sinais.

É importante ressaltar que, apesar disso, a criança realizou a maioria das habilidades comunicativas eliciadas pelo teste. A literatura relata que essas interações estimulam a comunicação e o desenvolvimento intelectual da criança, podendo interferir na velocidade de seu desenvolvimento e domínio linguístico ${ }^{(5)}$. Interessante observar que as duas habilidades não realizadas pela criança - "ouvindo" e "participando" - são interações de conversação com outras duas pessoas. Este dado corrobora com a literatura ${ }^{(13)}$, que mostra que crianças ouvintes com déficit cognitivo apresentam dificuldades para interações sociais com outras pessoas.

Assim, foi possível constatar que a criança apresenta-se na fase linguística, no estágio de um sinal, sendo visível o atraso em relação à linguagem. Comparando-se com a aquisição da linguagem de crianças surdas, filhas de pais surdos, expostas a língua materna desde o nascimento, um estudo evidenciou o início do estágio de um sinal por volta dos 6 meses de idade, indo até os 2 anos $^{(11)}$.

Em relação ao léxico, considerando os resultados do terceiro instrumento de avaliação aplicado, as 15 crianças participantes do referido estudo conseguiram denominar todas as 120 figuras do instrumento. As crianças apresentaram DE, DNE, DEM, C/ $\mathrm{CL} / \mathrm{Mm}$, assim como a participante desta pesquisa. Contudo, os dados $^{(11)}$ demonstram que o nível de reconhecimento adequado de figuras (DE) foi de 77,4\% pelas 15 crianças, enquanto a criança sujeito desta pesquisa denominou apenas $14,2 \%$ das figuras de forma esperada**.

Esse resultado aponta para um vocabulário muito restrito para sua idade. Porém, assim como averiguado também nos outros instrumentos, foi perceptível a tentativa da criança em sinalizar quando queria mostrar que conhece algo. Ela mostrou reconhecer mais da metade das figuras $(56,6 \%)$, pois as denominou, ou tentou denominar, de alguma forma.

No estudo citado ${ }^{(11)}$, também foi possível verificar que, conforme o aumento do PEL, há uma tendência de ocorrerem mais denominações esperadas. Crianças com menos de 4 anos e meio de exposição linguística, como a deste estudo, tiveram maior ocorrência de DNE, C/CL/Mm e ND do que aquelas com mais de 6 anos e meio de exposição. Contudo, a maior ocorrência $(62,5 \%)$ daquele grupo ainda foi de denominações esperadas. Entretanto, nem em relação ao PEL a criança deste estudo atingiu média parecida, em termos de vocabulário, quando comparada com crianças sem comorbidades. Logo, o tempo de privação de linguagem, mesmo colaborando para o atraso de linguagem da menina, sugere não ser o principal fator desencadeante desse fato.

A fonologia também foi avaliada por esse protocolo. Segundo a literatura ${ }^{(14)}$, em relação à ordem de aquisição da fonologia em língua de sinais, o PA é o primeiro aspecto a ser adquirido, seguido pelo M e CM. Observa-se, também, que as substituições desses aspectos tornam-se menos frequentes em idades mais avançadas. Desses parâmetros, a CM foi o mais alterado pela criança e o PA, o menos. Levando em consideração que a menina encontra-se na fase de aquisição da linguagem, ela está adquirindo os parâmetros na sequência prevista e, mesmo com mais dificuldade que as outras crianças, espera-se que as substituições que ela realiza tornem-se menos frequentes com o aumento da idade e do PEL.

Os sinais produzidos pela criança, em sua maioria, são com uma CM, com uma mão (1 m $1 \mathrm{~cm})$, ou duas mãos $(2 \mathrm{~m} 1 \mathrm{~cm})$. Houve a produção de um único sinal, de forma esperada, com duas mãos e CM diferente entre elas ( $2 \mathrm{~m} 2 \mathrm{~cm}$ ) - "esmalte". Até mesmo em situações de imitação foi verificado que a criança não consegue produzir sinais, conforme o padrão adulto, com $2 \mathrm{~m} 2 \mathrm{~cm}$ - "feijão". Conforme os dados encontrados no estudo de validação desse protocolo ${ }^{(11)}$, os sinais formados por uma $\mathrm{CM}$ possuem mais DE do que os sinais formados por $2 \mathrm{~m} 2 \mathrm{~cm}$.

Alguns autores apresentam explicações para este fato. Uma delas é que a criança deve perceber a forma correta da $\mathrm{CM}$ nas duas mãos. Uma segunda explicação é que algumas CM apresentam uma área relativamente pequena como ponto de

** No estudo referido havia um grupo de crianças com idade cronológica e tempo de exposição à LIBRAS próximas a da criança deste estudo de caso, possibilitando comparações em relação ao conhecimento de vocabulário de crianças surdas. 
contato, necessitando de um grau de controle motor fino não usual em crianças menores. Por último, formar sinais com duas mãos e distintas $\mathrm{CM}$, requer um nível relativamente avançado de coordenação ${ }^{(14)}$. Essas explicações vão ao encontro dos dados achados na criança deste estudo, visto que possui dificuldades motoras importantes, devido ao seu diagnóstico de paquigiria.

Conforme a literatura ${ }^{(11)}$, crianças com idade e PEL similares à da criança sujeito da pesquisa, já devem ter adquirido mais sinais com $2 \mathrm{~m} 2 \mathrm{~cm}$. O índice de denominação esperada foi de $68,33 \%$ para esses sinais, enquanto a menina deste estudo de caso, denominou apenas $6,25 \%$, conforme o esperado.

Visto que o vocabulário da língua nativa proporciona integração com o meio social, a implementação semântica será possível à medida que o inventário fonológico crescer, quanto ao número de fonemas. Assim, o desenvolvimento do léxico e da fonologia está interligado, mesmo que existam variações individuais ${ }^{(11)}$. No caso em estudo, o vocabulário defasado pode estar comprometendo outras áreas importantes para a aquisição e desenvolvimento adequados da linguagem.

Não foram encontradas, na literatura consultada, pesquisas que avaliassem a linguagem de crianças surdas com algum comprometimento neurológico associado. Porém, serão trazidas considerações sobre casos com ouvintes, visto que a aquisição da linguagem por crianças surdas pode ocorrer no mesmo período e nos mesmos estágios observados em crianças ouvintes, considerando algumas condições em relação ao input linguístico a que as crianças surdas têm acesso ${ }^{(11)}$.

Crianças ouvintes que apresentam déficit cognitivo possuem dificuldades na aquisição da linguagem e na alfabetização, apresentando linguagem receptiva mais preservada que a expressiva, sendo esta pouco elaborada, constituída por frases curtas, com poucos elementos de ligação, muitas vezes restrita ao verbo e ao objeto direto, vocabulário simples, com pouca criatividade nas narrações de contos. Apresentam, também, atraso global do neurodesenvolvimento, grave comprometimento da atenção, da memória, da capacidade visuoespacial e do controle motor fino, bem como das capacidades sociais. Demonstram pouco interesse pela terapia, dificuldades pedagógicas e ritmo evolutivo das capacidades cognitivas extremamente lento. A maioria das crianças iniciou as primeiras palavras com atraso, apresentando ainda mais dificuldade para a formação de frases e para a leitura. Os pacientes com retardo mental apresentaram maior déficit cognitivo no teste de vocabulário, embora tenha se observado intenção comunicativa, apesar das dificuldades linguísticas ${ }^{(13)}$.

Todas as dificuldades descritas acima confirmam o quadro da criança sujeito desta pesquisa. Assim, a surdez e o início da exposição à LIBRAS, a partir de 1 ano e meio de idade, não são, por si só, causadores do atraso na aquisição da linguagem da criança. Outros fatores extralinguísticos, mas que se relacionam fortemente com a linguagem, causados pelo déficit cognitivo, como comprometimento de atenção, da memória e dos aspectos motor e visuoespacial, afetam a aquisição da LIBRAS, especialmente por ser uma língua de modalidade visuoespacial e necessitar de movimentos motores finos para a sinalização.

Ainda se considerarmos que a criança tem diagnóstico de paquigiria no hemisfério direito, veremos que esse hemisfério é associado às funções cognitivas de atenção, percepção e memória visuoespacial, esquema corporal, inteligência social e emocional e reconhecimento de expressões faciais ${ }^{(15)}$, funções muito ligadas aos aspectos necessários para a utilização da LIBRAS.

A literatura demonstra que há associação entre o atraso no desenvolvimento da linguagem e o número total de atos comunicativos das crianças surdas, ou seja, as que interagem mais, apresentam menos atraso no desenvolvimento da linguagem ${ }^{(5)}$. Embora todos os dados das avaliações realizadas tenham se mostrado defasados, a menina deste estudo revelou grande intenção comunicativa, apesar das limitações, e isso pode estar auxiliando-a a conseguir uma comunicação efetiva.

Crianças com déficit cognitivo que apresentam atraso motor e de linguagem desenvolverão, no futuro, diversas dificuldades acadêmicas, nos mais variados domínios da cognição. Isso reflete a necessidade da criação de estratégias de estimulação pedagógica e fonoaudiológica precoces para o grupo de crianças com esse quadro, pois as dificuldades escolares já serão previstas. Após esse estágio precoce, essas crianças acabam por se adaptar ao restrito meio social e não acompanham as atividades escolares, como relatado em estudo com adolescentes, cujos avanços foram bastante limitados após esse período ${ }^{(13)}$.

Os achados deste estudo trazem implicações importantes para os programas de intervenção fonoaudiológica com a criança surda. Além de trazer um aprofundamento sobre a paquigiria, que pode, também, ser estendida a outros déficits cognitivos, que, quando associados à surdez, devem receber atenção especial dos profissionais da saúde. O estudo poderá facilitar o planejamento terapêutico desses profissionais, além de proporcionar-lhes alargamento de visão para os casos de pacientes com déficit cognitivo que utilizam outra modalidade de comunicação, para que tenham toda a assistência possível e uma equipe interdisciplinar envolvida e competente, atuando em seu favor. Por fim, acreditamos que este estudo contribuirá para a análise da evolução linguística no processo terapêutico fonoaudiológico no contexto comunicativo.

\section{COMENTÁRIOS FINAIS}

A participante do estudo demonstrou atraso considerável na linguagem compreensiva, mas principalmente na expressiva, com grande defasagem de vocabulário. Entretanto, demonstrou ter habilidades pragmáticas e grande intenção comunicativa. Um achado importante foi que o tempo de privação linguística sugere não ser o principal fator desencadeante do atraso na aquisição de linguagem da criança, sendo que a paquigiria está intervindo de forma mais evidente nesse processo.

Foi perceptível, durante a aplicação dos testes propostos, 
que a falta de atenção e contato visual atrapalham muito a criança em sua comunicação, pois são essenciais para o desenvolvimento de qualquer língua, mas principalmente para a língua de sinais. A intenção comunicativa, que também foi percebida ao longo das avaliações, mostrou que a menina não deixa de se comunicar - embora faça uso preferencial de meios não gramaticais, do ponto de vista linguístico - o que tem sido essencial para o seu desenvolvimento.

A criança com dificuldades na área da linguagem, inclusive quando usuária de LIBRAS, deve receber todo o apoio e estimulação das pessoas que convivem diretamente com ela. Neste caso, é de extrema importância a utilização da LIBRAS por toda família da criança, assim como pelos professores e colegas da escola e pelos profissionais da área clínica, para que tenha mais possibilidades de desenvolver-se linguisticamente, de forma mais rápida e adequada.

Nessa abordagem, o fonoaudiólogo fluente em LIBRAS pode colaborar para a identificação das prioridades e necessidades de comunicação da criança, estabelecendo metas e ações que contribuam para a diminuição ou para a superação das defasagens comunicativas. Assim, as crianças usuárias dessa língua poderão receber apoio e estímulos necessários para seu melhor desenvolvimento, proporcionando-lhes melhor qualidade de vida.

Além disso, é fundamental que o profissional que acompanha o quadro neurológico conheça o trabalho do fonoaudiólogo com essas crianças, para que, assim, elas possam ser encaminhadas quando necessário, sem que ocorra maior defasagem no futuro.

\section{AGRADECIMENTOS}

À Universidade Federal de Ciências da Saúde de Porto Alegre (UFCSPA), pelo incentivo à pesquisa, processo número $12 / 946$.

\section{REFERÊNCIAS}

1. Fernandes DMZ, Lima MCMP, Gonçalves VMG, Fraçozo MFC. Acompanhamento do desenvolvimento da linguagem de lactentes de risco para surdez. Rev Soc Bras Fonoaudiol. 2011;16(1):30-6.
2. Diament A, Cypel S. Neurologia Infantil. 4a. ed. São Paulo: Atheneu; 2005.

3. Maia MGL, Caboclo LOSF, Júnior HC, Garzon E, Sakamoto AC, Yakubian EMT. Fusos extremos na era da ressonância magnética: características clínicas, eletrográficas e de neuroimagem. J Epilepsy Clin Neurophysiol. 2005;11(4):163-9.

4. Curti L, Quintas TA, Goulart BNG, Ciari BM. Habilidades pragmáticas em crianças deficientes auditivas: estudo de casos e controles. Rev Soc Bras Fonoaudiol. 2010;15(3):390-4.

5. Lichtig I, Couto MIV, Leme VN. Perfil pragmático de crianças surdas em diferentes fases linguísticas. Rev Soc Bras Fonoaudiol. 2008;13(3):251-7.

6. Moura MC, Harrison KMP. A inclusão do surdo na universidade: mito ou realidade? Cadernos de Tradução. 2010;2(26):333-58.

7. Quadros RM, Cruz CR. Língua de sinais: instrumentos de avaliação. Porto Alegre: Artmed; 2011.

8. Quadros RM, Karnopp LB. Língua de sinais brasileira: estudos linguísticos. Porto Alegre: Artmed; 2009.

9. Quadros RM. Avaliação da língua de sinais em crianças surdas na escola. Letras de Hoje. 2004;39(3):297-309.

10. Lichtig I. Programa de intervenção fonoaudiológica em famílias de crianças surdas (PIFFCS). São Paulo: Pro-Fono; 2004. p. 39-80.

11. Cruz CR. Proposta de instrumento de avaliação da consciência fonológica, parâmetro configuração de mão, para crianças surdas utentes da língua de sinais brasileira [dissertação]. Porto Alegre: Faculdade de Letras, Pontifícia Universidade Católica do Rio Grande do Sul; 2008.

12. Barbosa FV. Avaliação das habilidades comunicativas de crianças surdas: a influência do uso da língua de sinais e do Português pelo examinador bilíngue [tese]. São Paulo: Faculdade de Medicina, Universidade de São Paulo; 2007.

13. Martins RHG, Bueno EC, Fioravanti MP. Síndrome de RubinsteinTaybi: anomalias físicas, manifestações clínicas e avaliação auditiva. Rev Bras Otorrinolaringol. 2003;69(3):427-31.

14. Karnopp LB. Aquisição fonológica na Língua Brasileira de Sinais: Estudo longitudinal de uma criança surda [dissertação]. Porto Alegre: Pontifícia Universidade Católica do Rio Grande do Sul; 1999.

15. Myers PS. Toward a definition of RHD syndrome. Aphasiology. 2001;15(10/11):913-8. 